\title{
Generalized Form of a 4x4 Magic Square
}

\author{
Bhavya Gupta \\ Department of Chemical Engineering, Thapar University, Patiala, India
}

\begin{abstract}
A magic square is $\mathrm{N}^{*} \mathrm{~N}$ matrix containing integers and addition result of each row, column and diagonally get the same value. The commonly used methods of constructing magic squares are the cross diagonals method for doubly even. This method does not use mathematical formula in the construction of the magic square. We will find the generalized form of a 4 X 4 magic square with help of 4 X 4 .
\end{abstract}

Keywords: Magic Square, Magic Sum, Bhavya Square.

\section{INTRODUCTION}

Magic squares have turned up throughout history, some in a mathematical context, and others in philosophical or religious contexts. According to legend, the first magic square was discovered in China by an unknown mathematician sometime before the first century A.D. It was a magic square of order three thought to have appeared on the back of a turtle emerging from a river. Other magic squares surfaced at various places around the world in the centuries following their discovery. Some of the more interesting examples were recorded in Europe during the 1500s. Cornelius Agrippa wrote De Occulta Philosophia in 1510. In it he describes the spiritual powers of magic squares and produces some squares of orders from three up to nine. His work, although influential in the mathematical community, enjoyed only brief success, for the counter-reformation and the witch hunts of the Inquisition began soon thereafter: Agrippa himself was accused of being allied with the devil. Although this story seems outlandish now, we cannot ignore the strange mystical ties magic squares seem to have with the world and nature surrounding us, above and beyond their mathematical significance.

We define a semi-magic square to be a square matrix whose entries are nonnegative integers and whose rows and columns (called lines in this setting) sum to the same number. A magic square is a semi-magic square whose main diagonals also add up to the line sum. A symmetric magic square is a magic square that is a symmetric matrix.

A pandiagonal magic square is a semi-magic square whose diagonals parallel to the main diagonal from the upper left to the lower right, wrapped around (i.e., continued to a duplicate square placed to the left or right of the given one), add up to the line sum. We caution the reader about clashing definitions in the literature. For example, some people would reserve the term "magic square" for what we will call a traditional magic square, a magic square of order $\mathrm{n}$ whose entries are the integers $1,2, \ldots, \mathrm{n}^{2}$.

In the traditional case for each order there is a fixed number of traditional magic squares.

The magic squares are of three orders:

1. Odd order magic square

2. Singly even magic square: which are divisible by 2 .

3. Doubly even magic square: which are divisible by 4 .

\section{SOME LITERARY WORK}

The Lo Shu Square: The Lo Shu square is an ancient $3 \times 3$ magic square which features in Chinese divination. Some people claim that it may date to around $2800 \mathrm{BCE}$.

\begin{tabular}{|l|l|l|}
\hline 4 & 9 & 2 \\
\hline 3 & 5 & 7 \\
\hline 8 & 1 & 6 \\
\hline
\end{tabular}

All other normal $3 \times 3$ magic squares are rotations and/or reflections of the Lo Shu square.

The Jaina Square

This famous square is described in Magic Squares and Cubes by W.S. Andrews as dating to the 11th Century CE.

\begin{tabular}{|l|l|l|l|}
\hline 7 & 12 & 1 & 14 \\
\hline 2 & 13 & 8 & 11 \\
\hline 16 & 3 & 10 & 5 \\
\hline 9 & 6 & 15 & 4 \\
\hline
\end{tabular}

The Jaina Square (so named because it is also found in a 12th or 13th Century Jaina/Jain inscription at Khajuraho, Northern India) is an example of what has been termed a 'diabolic' or 'most-perfect' magic square because it has additional properties that enable the summation constant (T) to be produced in many different ways (more on mostperfect magic squares later).

The Dürer Square: This $4 \times 4$ magic square is featured in Albrecht Dürer's (1471-1528) famous engraving "Melancolia" (1514). 16321351011896712415141

\begin{tabular}{|l|l|l|l|}
\hline 16 & 3 & 2 & 13 \\
\hline 5 & 10 & 11 & 8 \\
\hline 9 & 6 & 7 & 12 \\
\hline 4 & 15 & 14 & 1 \\
\hline
\end{tabular}

Note the date 1514 in the bottom row.

\section{III.MAGIC SQUARE 4X4}

The traditional magic square of order $4 \times 4$ can be made easily with magic sum 34 Total no. of possible magic squares with these elements $=880$ And if we want magic square of order $4 \times 4$ with sum more than 34 we have a formula $\mathrm{Q}=($ desired sum -34$) / 4$ In this, $\mathrm{Q}$ will be added to all terms of magic square to get new magic square of

\begin{tabular}{|l|l|l|l|}
\hline 12 & 6 & 15 & 1 \\
\hline 13 & 3 & 10 & 8 \\
\hline 2 & 16 & 5 & 11 \\
\hline 7 & 9 & 4 & 14 \\
\hline
\end{tabular}


International Advanced Research Journal in Science, Engineering and Technology

desired sum .By this we only get the same elements magic square but no alternate elements square. But we don't have any general formula in which we can just put the values and get the new square. So here, is generalised form of 4x4 magic square:

Bhavya Number Magic Square

1. It will calculate the square for the given four numbers For even sum:

\begin{tabular}{|l|l|l|l|}
\hline $\mathrm{A}$ & $\mathrm{B}$ & $\mathrm{C}$ & $\mathrm{D}$ \\
\hline $\mathrm{D}+\left(\left(\mathrm{z}_{1} / 2\right)+1\right)$ & $\mathrm{C}-\left(\left(\mathrm{z}_{1} / 2\right)+1\right)$ & $\mathrm{B}-\left(\left(\mathrm{z}_{1} / 2\right)-1\right)$ & $\mathrm{A}+\left(\left(\mathrm{z}_{1} / 2\right)-1\right)$ \\
\hline $\mathrm{B}-\left(\mathrm{z}_{1} / 2\right)$ & $\mathrm{A}+\left(\mathrm{z}_{1} / 2\right)$ & $\mathrm{D}+\left(\mathrm{z}_{1} / 2\right)$ & $\mathrm{C}-\left(\mathrm{z}_{1} / 2\right)$ \\
\hline $\mathrm{C}-1$ & $\mathrm{D}+1$ & $\mathrm{~A}-1$ & $\mathrm{~B}+1$ \\
\hline
\end{tabular}

It will give a magic square of even sum, if these variables

$\mathrm{A}, \mathrm{B}, \mathrm{C}$ and $\mathrm{D}$ follow these conditions:

1. $\mathrm{B}-\mathrm{A}=\mathrm{D}-\mathrm{C}+\mathrm{z}_{1}$ where $\mathrm{z}_{1}$ is Even

2. $(\mathrm{C}-\mathrm{B}) \geq 5$

3. $\mathrm{B}-\mathrm{A} \geq 5$

Where $\mathrm{A}, \mathrm{B}, \mathrm{C}$ and $\mathrm{D}$ are given numbers.

Features of this magic square:

1. It is valid on all sums, if following the above conditions.

2. It will give 56 combinations for magic even sum.

3 . It is not derived from basic square with magic sum 34 so it is easy to calculate.

4. With rotation and reflection, it also gives alternate magic squares with same elements.

For example,

Give magic square with no. 4,14,21,25

Solution.. Given,

$\mathrm{A} 0=4, \mathrm{~B}=14, \mathrm{C}=21, \mathrm{D}=25, \mathrm{z}_{1}=6$

So, sum is $A+B+C+D=64$

\begin{tabular}{|l|l|l|l|}
\hline 4 & 14 & 21 & 25 \\
\hline 29 & 17 & 12 & 6 \\
\hline 11 & 7 & 28 & 18 \\
\hline 20 & 26 & 4 & 15 \\
\hline
\end{tabular}

This is the required magic square with 52 combinations.

For odd sum:

\begin{tabular}{|l|l|l|l|}
\hline $\mathrm{A}$ & $\mathrm{B}$ & $\mathrm{C}$ & $\mathrm{D}$ \\
\hline $\mathrm{D}+\left(\left[\mathrm{z}_{1} / 2\right]+1\right)$ & $\mathrm{C}-\left(\left[\mathrm{z}_{1} / 2\right]+1\right)$ & $\mathrm{B}-\left(\left[\mathrm{z}_{1} / 2\right]-1\right)$ & $\mathrm{A}+\left(\left[\mathrm{z}_{1} / 2\right]-1\right)$ \\
\hline $\mathrm{B}-\left[\mathrm{z}_{1} / 2\right]$ & $\mathrm{A}+\left[\mathrm{z}_{1} / 2\right]$ & $\mathrm{D}+\left[\mathrm{z}_{1} / 2\right]$ & $\mathrm{C}-\left[\mathrm{z}_{1} / 2\right]$ \\
\hline $\mathrm{C}-1$ & $\mathrm{D}+1$ & $\mathrm{~A}-1$ & $\mathrm{~B}+1$ \\
\hline
\end{tabular}

It will give a magic square of odd sum, if these variables $\mathrm{A}, \mathrm{B}, \mathrm{C}$ and $\mathrm{D}$ follow these conditions:
1. $\mathrm{B}-\mathrm{A}=\mathrm{D}-\mathrm{C}+\mathrm{z}_{1}$
Where $\mathrm{z}_{1}$ is odd
2. $(\mathrm{C}-\mathrm{B}) \geq 5$

3. $\mathrm{B}-\mathrm{A} \geq 5$

Where $\left[\mathrm{z}_{1} / 2\right]=$ greatest integer of $\mathrm{z}_{1} / 2$

Features of this magic square:

1. It is valid on all sums, if following the above conditions.

2. It will give 36 combinations for magic odd sum.

3 . It is not derived from basic square with magic sum 34 so it is easy to calculate.

4. With rotation and reflection, it also gives alternate magic squares with same elements.

For example,

Give magic square with numbers 5,14,21,25.

Solution. Given, $A=5, B=14, C=21, D=25, z_{1}=5$

So, sum is $\mathrm{A}+\mathrm{B}+\mathrm{C}+\mathrm{D}=65$

This is the required magic square with 36 combinations.

\begin{tabular}{|l|l|l|l|}
\hline 5 & 14 & 21 & 25 \\
\hline 28 & 18 & 13 & 6 \\
\hline 12 & 7 & 27 & 19 \\
\hline 20 & 26 & 4 & 15 \\
\hline
\end{tabular}

Combined magic square

\begin{tabular}{|l|l|l|l|}
\hline $\mathrm{A}$ & $\mathrm{B}$ & $\mathrm{C}$ & $\mathrm{D}$ \\
\hline $\mathrm{D}+\left(\left[\mathrm{z}_{1} / 2\right]+1\right)$ & $\mathrm{C}-\left(\left[\mathrm{z}_{1} / 2\right]+1\right)$ & $\mathrm{B}-\left(\left[\mathrm{z}_{1} / 2\right]-1\right)$ & $\mathrm{A}+\left(\left[\mathrm{z}_{1} / 2\right]-1\right)$ \\
\hline $\mathrm{B}-\left[\mathrm{z}_{1} / 2\right]$ & $\mathrm{A}+\left[\mathrm{z}_{1} / 2\right]$ & $\mathrm{D}+\left[\mathrm{z}_{1} / 2\right]$ & $\mathrm{C}-\left[\mathrm{z}_{1} / 2\right]$ \\
\hline $\mathrm{C}-1$ & $\mathrm{D}+1$ & $\mathrm{~A}-1$ & $\mathrm{~B}+1$ \\
\hline
\end{tabular}

It will give a magic square of any sum, if these variables $\mathrm{A}, \mathrm{B}, \mathrm{C}$ and $\mathrm{D}$ follow these conditions:

1. $\mathrm{B}-\mathrm{A}=\mathrm{D}-\mathrm{C}+\mathrm{z}_{1}$

2. $(\mathrm{C}-\mathrm{B}) \geq 5$

3. $\mathrm{B}-\mathrm{A} \geq 5$

Where $\left[z_{1} / 2\right]=$ greatest integer of $z_{1} / 2$

Comparison between Bhavya Number square and Other squares:

\begin{tabular}{|l|l|}
\hline Bhavya Number Square & Other squares \\
\hline $\begin{array}{l}\text { It is not derived from any } \\
\text { square }\end{array}$ & $\begin{array}{l}\text { They are derived from } \\
\text { basic square }\end{array}$ \\
\hline $\begin{array}{l}\text { It is easy to calculate as } \\
\text { we just have to put values }\end{array}$ & $\begin{array}{l}\text { They are not easy to } \\
\text { calculate as they are } \\
\text { derived from basic square }\end{array}$ \\
\hline It is valid on all sums & $\begin{array}{l}\text { They are not valid on all } \\
\text { sums as by increasing } \\
\text { number their calculations } \\
\text { become more and more } \\
\text { difficult }\end{array}$ \\
\hline
\end{tabular}

Remarks: Transformations can also be made from

Even to even sum

By using formula stated down

$|\mathrm{b}-\mathrm{a}| / 4$ quotient of this will be added to all elements of magic square and reminder will be added to (i)C and D if $\mathrm{y}$ is 5 .

(ii) A and B or C and D by our choice if $\mathrm{y}$ is greater than equal to 5 .

Odd to odd sum

By using formula stated down $|b-a| / 4$ quotient of this will be added to all elements of magic square and reminder will be added to (i)C and D if y is 5 .

(ii) $\mathrm{A}$ and $\mathrm{B}$ or $\mathrm{C}$ and $\mathrm{D}$ by our choice if $\mathrm{y}$ is greater than equal to 5 .

Even to Odd sum

$|\mathrm{b}-\mathrm{a}| \mathrm{/4}$ quotient of this will be added to all elements of magic square and reminder can be added to any element by maintaining the conditions.

Where, $b=$ second sum $a=$ first sum $\mathrm{y}=$ difference between $\mathrm{C}$ and $\mathrm{B}$

\section{REFERENCES}

1. C. A. Pickover, The Zen of Magic Squares, Circles, and Stars, Princeton University Press, Princeton, 2002.

2. W. S. Andrews, Magic Squares and Cubes, 2nd ed., Dover, New York, 1960.

3. Matthias Beck, Moshe Cohen, Jessica Cuomo, and Paul Gribelyuk, The number of "magic" squares, cubes and hypercubes, October ed.,the American mathematical monthly,2003.

4. EffangaOkonEffanga, UweEtimEdeke, A mathematical model for constructing magic squares, Journal of Mathematical and Computational Science, Vol 3, No 2 (2013), 466-481. 